\title{
THE RELATIONSHIP BETWEEN TRANSFORMATIONAL LEADERSHIP, INTEGRITY AND AN ETHICAL CLIMATE IN ORGANISATIONS
}

\begin{abstract}
Authors:
Anja S. van Aswegen ${ }^{1}$

Amos S. Engelbrecht ${ }^{1}$
\end{abstract}

\section{Affiliations:}

${ }^{1}$ Department of Industrial

Psychology, Stellenbosch

University, South Africa

\section{Correspondence to:}

Amos Engelbrecht

e-mail:

ase@sun.ac.za

\section{Postal address:}

PO Box 3543, Stellenbosch, 7602, South Africa

\section{Keywords:}

transformational

leadership; integrity;

ethical culture; values;

South Africa

\section{Dates:}

Received: 10 Nov. 2008

Accepted: 08 Sept. 2009

Published: 30 Oct. 2009

How to cite this article: Van Aswegen, A.S., \& Engelbrecht, A.S. (2009). The relationship between transformational leadership, integrity and an ethical climate in organisations. $S A$ Journal of Human Resource Management/SA Tydskrif vir Menslikehulpbronbestuur 7(1), Art. \#175, 9 pages. DOI: 10.4102/sajhrm.v7i1.175

\section{This article is available} at: http://www.sajhrm.co.za

(C) 2009. The Authors. Licensee: OpenJournals Publishing. This work is licensed under the Creative Commons Attribution License.

\begin{abstract}
By effectively utilising the transformational leadership process, an organisation's culture can be transformed into one that encourages ethical behaviour. The aim of this study was to validate a theoretical model to explain the relationships between leadership, integrity and an ethical climate. A non-probability sample of employees $(n=203)$ from medium to large companies was used. Data were analysed by item, factor and multiple regression analyses. The results revealed that transformational leadership has a positive effect on the dimensions of an ethical climate. No convincing support was found for the proposition that integrity moderates the relationship between transformational leadership and the dimensions of an ethical climate.
\end{abstract}

\section{INTRODUCTION}

Business ethics has emerged as an important issue in society in the past decade and is considered critical to business success in the long term. The benefits of an ethically orientated culture are many, including increased effectiveness due to a strengthened organisational culture, and increased effort and lower levels of turnover resulting from greater organisational commitment (Jones, 2007; McDonald, 2009; Yukl, 2006). South Africa is experiencing an increasing awareness of unethical practices and public distrust of business in general is widespread (Spangenberg \& Theron, 2005). Typical unethical leadership behaviour and practices that occur in many organisations include corruption, bribery, intimidation, fraud, lying, favouritism and endangerment of the physical environment (Banerji \& Krishnan, 2000; Malan \& Smit, 2001). Due to disappointing public organisation scandals that have been exposed, a return to ethics in the organisation has become vital and organisational leaders have to realise how important ethical leadership is. Not only are ethical practices essential to overcome the increasing occurrence of scandals and its negative consequences, but such practices also affect the organisation's profitability positively on account of its reputation as an honest and trustworthy employer and business partner (Fulmer, 2004).

The ethical climate of an organisation, which is the shared perceptions of what ethically correct behaviour is and how ethical issues/dilemmas should be handled, both reflects and defines the ethics of an organisation (Jones, 2007; McDonald, 2009; Victor \& Cullen, 1987). An ethical culture is believed to influence employees to be more loyal to their organisations, thereby contributing to the unleashing of their productive and creative potential within the work environment and boosting business performance (Rossouw, 1997).

The solution to ethical problems ultimately lies in the establishment of moral and competent leadership (Bass \& Steidlmeier, 1999; Kanungo \& Mendonca, 1996; Malan \& Smit, 2001; McDonald, 2009). A contemporary definition of ethical leadership is leadership that engages in ethical conduct that is based on right or wrong behaviour towards members of society (Odom \& Green, 2003). As Kanungo and Mendonca (1996) have observed, the beliefs and values, the vision and, most importantly, the actions of the leader can be seen as setting the ethical tone and standards for the unit or organisation. According to Bass and Steidlmeier (1999), the ethics of leadership rests on three pillars: firstly, the moral character of the leader, secondly, the ethical values embedded in the leader's vision and articulation thereof and, lastly, the morality of the choices and actions that leaders and followers engage in and pursue to realise the ethical vision.

Burns's (1978) theory of transforming leadership, which prescibes the nature of morally good leadership, rests on a set of moral assumptions about the relationship between leaders and followers. Transforming leaders are concerned with end-values such as liberty, justice and equality, and with raising followers to higher levels of morality.

Transformational leadership alone is not a guarantee of ethical leadership behaviour, although many of the transformational behaviours are synonymous with ethical behaviours (Odom \& Green, 2003; Parry \& Proctor-Thomson, 2002). Ciulla (2004) believes that the body of research on transformational leadership is promising because it includes empirical research into a theory that was constructed to address the basic moral problems of leadership. According to Bass and Steidlmeier (1999), leaders are truly (authentic as opposed to pseudo) transformational when they increase awareness of what is right, good and important, and when they raise followers to become leaders who go beyond their selfinterest for the good of their organisation.

Corrupt behaviour is not impulsive, it is a premeditated act, and this highlights the importance and power of sound ethical personal values for preventing unethical behaviour (Malan \& Smit, 2001). Research strongly supports the conclusion that the ethical philosophies and values of management have a major impact on the ethical choices and behaviour of employees (McDonald, 2009). Ethical leadership should be guided by values such as individual moral responsibility, caring for others, mutual respect, human fulfilment, honour and integrity (Gardner, cited in Engelbrecht, 2001). Leaders who have a high regard for integrity are more respectful to co-workers and more loyal to 


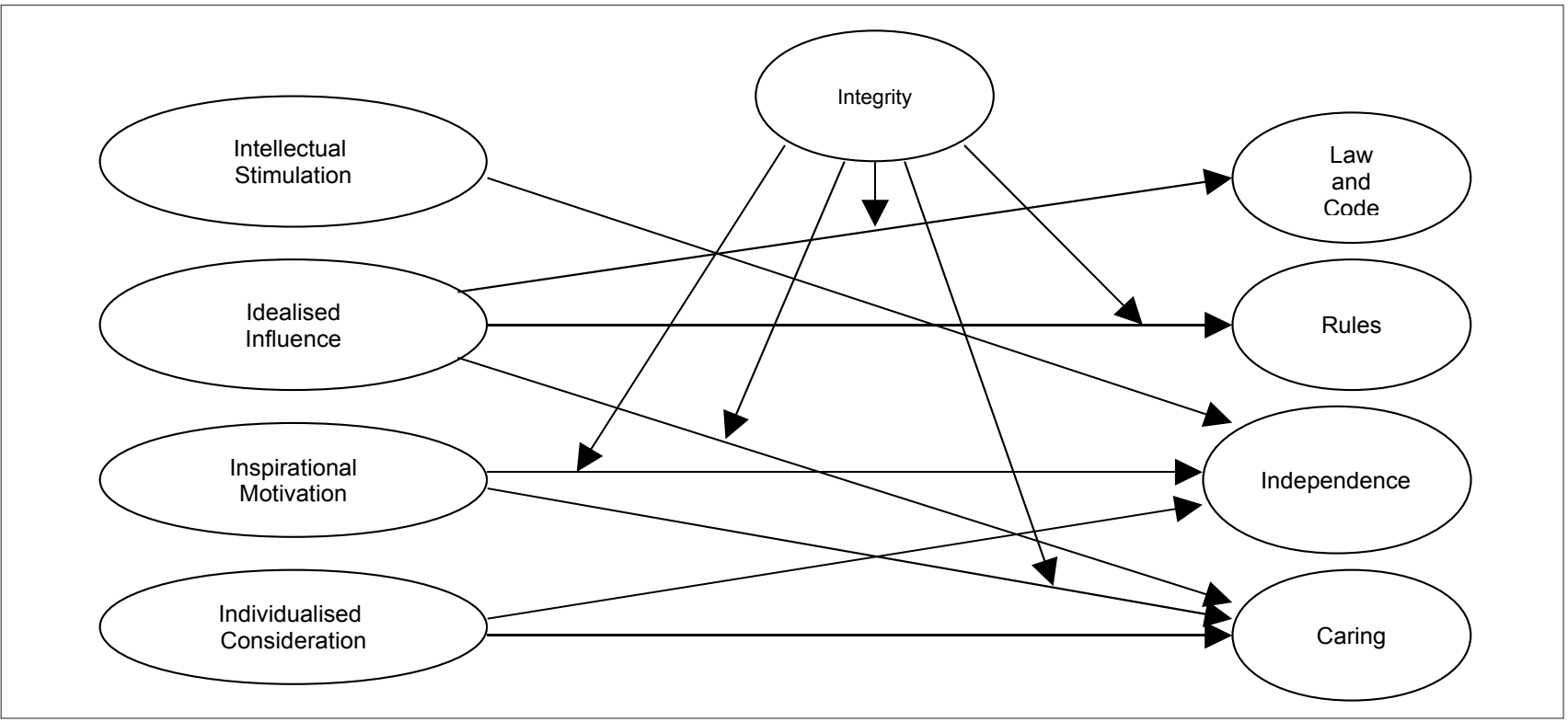

FIGURE 1

A conceptual model of the relationships between transformational leadership, integrity and the dimensions of an ethical climate

the organisation, and are therefore less likely to take part in counterproductive behaviour (Mikulay \& Goffin, 2007; Ones, Viswesvaran \& Schmidt, 2003). To ensure the desired ethical leadership behaviour, it is necessary to identify the value systems of socialised transformational leaders (Engelbrecht, 2001). According to Engelbrecht (2001), ethical leader behaviour is directed by the underlying values of transformational leaders, such as self-transcendence, developmental orientation, team rewards orientation, empowerment and interactional justice. Research results have indicated that transformational leaders contribute to the development of a climate of procedural and interactionaljusticein organisations (Engelbrecht\&Chamberlain, 2005; Krafft, Engelbrecht \& Theron, 2004).

\section{Purpose of the study}

The aim of this study was to further develop and test a theoretical model that reveals the factors that determine an ethical climate in organisations through the exploration of the ethical values of transformational leaders. Integrity, in particular, is recognised in the literature as a core ethical value of transformational leaders (Ciulla, 2004; Engelbrecht, 2001; Kanungo \& Mendonca, 1996; Palanski \& Yammarino, 2009; Yukl, 2006). The positive effect of integrity on transformational leadership revealed that leaders will only be perceived as transformational if they display consistency in words and actions. Leaders play a key role in determining the ethical climate of an organisation. Therefore, the positive relationship between transformational leadership and an ethical climate emphasises the importance of transformational leadership behaviour in developing leaders and ethical organisations. The present study aimed to analyse the relationship that exists between leadership and an ethical climate through investigating the specific relationships that are assumed to exist between the dimensions of transformational leadership and an ethical climate. The specific leadership-climate linkages moderated by leader integrity are also explicated in the model (see Figure 1).

The following sections explain the relationships between the variables depicted in the theoretical model.

\section{Transformational leadership and an ethical climate}

According to Bass and Avolio (1994), leaders are truly transformational when they increase awareness of what is right, good and important, and when they raise followers up into leaders who go beyond their self-interest for the good of the organisation. Bass and Avolio (1994) identified four dimensions of transformational leadership. These are idealised influence, inspirational motivation, intellectual stimulation and individualised consideration. Idealised influence or charisma refers to the behaviour of leaders that results in their being rolemodels for their followers. These leaders are admired, respected and trusted because of their consideration of the needs of others over their personal needs. Inspirational motivation refers to the behaviour of leaders that motivate and inspire those around them by providing meaning and challenge to their followers' work. They ensure their followers' involvement by envisioning attractive future states and by displaying optimism and enthusiasm. Intellectual stimulation refers to the way in which leaders stimulate their followers' efforts to be innovative and creative by questioning assumptions, reframing challenges and approaching old situations in different ways. Individualised consideration is reflected when a leader pays special attention to each individual's needs for self-actualisation, growth and performance by acting as a coach or mentor.

An ethical climate is a subset of the organisational climate, and involves normative values and beliefs concerning moral issues that are shared by the employees of the organisation (Jones, 2007; Weber, 1995). The ethical work climate constitutes the prevailing perceptions of typical organisational practices and procedures that have ethical content (Victor \& Cullen, 1988). Victor and Cullen (1988) identified four dimensions of a corporate ethical climate, namely rules, independence, caring, and law and code climate.

When the organisation's ethical climate is not clear and positive, employees will often look to leaders for guidance to handle ethical dilemmas (Kidwell \& Martin, 2005). Actions speak louder than words, and what the leader values and does will set the ethical tone for decision making at all levels and create the moral environment of an organisation. It is the leader's personal conduct that determines the effectiveness of codes, policies, procedures and support structures. An organisation's ethical climate should be a natural overflow of leaders' commitment to ethical principles and values expressed in their daily struggle to 
live by them (Banerji \& Krishnan, 2000; Kanungo \& Mendonca, 1996).

Studies have investigated the separate impact of the various dimensions of transformational leadership on performance and attitudes (Banerji \& Krishnan, 2000). It is therefore logical to assume that the different aspects of transformational leadership will be related to the different dimensions of an ethical climate in different ways. The transformational leadership dimensions can be linked to specific dimensions of an ethical climate as follows:

Intellectual stimulation may lead to the dimension of an independence climate, as this creates a climate that supports followers in questioning their own values, beliefs and expectations. It also enables followers to make their own decisions about what is right and wrong (Victor \& Cullen, 1988). The leader is instrumental in getting followers to re-examine assumptions that may inhibit creativity and innovation (Banerii \& Krishnan, 2000; Bass \& Avolio, 1994; Odom \& Green, 2003). Therefore, the following can be postulated:

Hypothesis 1: A positive relationship exists between intellectual stimulation and an independence climate.

Idealised influence may lead to the following climate dimensions:

- Law and code: In this climate, the law and professional standards are put above all other considerations (Victor \& Cullen, 1988). The leader will always consider the applicable law whenever a decision has to be made, and can be counted on to do the right thing. The leader demonstrates high ethical and moral standards and thereby becomes a role-model who is respected and trusted by his or her followers.

- Rules climate: In this climate, it is required to strictly follow the company's procedures (Victor \& Cullen, 1988). This climate would be evident if the leaders live out the ethical standards that have been set, in other words match their actions to their words. This leads to integrity, resulting in the followers trusting their leaders.

- Caring climate: Leaders in this climate always consider the good of their followers, and put others before themselves (Victor \& Cullen, 1988). This sets an example for followers to do the same, and the leader is admired and trusted because of such behaviour. Followers will want to emulate the leader.

Therefore, the following can be postulated:

Hypothesis 2: A positive relationship exists between idealised influence and a law and code climate.

Hypothesis 3: A positive relationship exists between idealised influence and a rules climate.

Hypothesis 4: A positive relationship exists between idealised influence and a caring climate.

Inspirational motivation may lead to the following dimensions:

- Independence climate: This climate involves that people are expected to follow their own personal moral and ethical beliefs (Victor \& Cullen, 1988). Leaders with inspirational motivation behave in ways that motivate and inspire those around them by providing meaning and a challenge to followers' tasks, while allowing them autonomy to decide for themselves what is right or wrong. Inspirational leaders raise awareness of what is important in a problem and encourage the use of 'gut feelings' and intuition in solving problems (Bass \& Avolio, 1994). The leader gives his or her followers the freedom to decide their own ethical principles.

- Caring climate: The leader remains optimistic about likely outcomes despite setbacks that may occur, constantly providing encouragement and feedback to followers, as well as boosting their confidence in achieving success. The leader reminds them of the mission, and is concerned about the larger picture. Inspirational leaders are likely to enhance the enabling and empowerment of their followers and their commitment to search for solutions to problems (Banerji \& Krishnan, 2000; Bass \& Avolio, 1994; Odom \& Green, 2003).

Therefore, the following can be postulated:

Hypothesis 5: A positive relationship exists between inspirational motivation and an independence climate.

Hypothesis 6: A positive relationship exists between inspirational motivation and a caring climate.

Individualised consideration can be linked to the following dimensions of an ethical climate:

- Independence climate: The leader treats each follower individually, as individual differences in terms of needs and desires are recognised. This allows followers to make their own decisions with regard to ethical issues, without the leader coercing them to follow a certain course of action.

- Caring climate: This refers to the degree that people in the company consider the best interests of others, through acts of benevolence. The individually considerate leader takes the needs and interests of the followers into account.

The following can be postulated from the above assumptions and findings:

Hypothesis 7: A positive relationship exists between individualised consideration and an independence climate. Hypothesis 8: A positive relationship exists between individualised consideration and a caring climate.

\section{Integrity and transformational leadership}

In a comprehensive review of management literature, Palanski and Yammarino (2007) classified the various meanings of integrity into five general categories, namely integrity as wholeness; integrity as consistency between words and actions; integrity as consistency in adversity; integrity as being true to oneself; and integrity as moral or ethical behaviour. Integrity means that an individual's behaviour is consistent with espoused moral values, and that the person is honest and trustworthy (Yukl, 2006). Most scholars consider integrity to be a requirement for ethical and effective leadership (Palanski \& Yammarino, 2009; Storr, 2004; Yukl, 2006). It is a firm belief in good leadership that leaders should walk their ethical talk by living and not merely promoting the organisation's value system and design (Davis \& Rothstein, 2006; Malan \& Smit, 2001). Leaders should personally demonstrate commitment and loyalty to the organisation by behaving and leading with integrity and by showing what it means to behave consistently and congruently with what they confess (Malan \& Smit, 2001). The leader gains influence by demonstrating important personal characteristics, which are by-products of his or her strong value system (Carlson \& Perrewe, 1995).

Trustworthiness and integrity have been identified as essential aspects of effective transformational leaders (Palanski \& Yammarino, 2009). Leaders communicate their values and standards most directly through their actions and, subsequently, through how they direct their attention, respond to problems and formulate strategies (Trevino, cited in Cohen, 1993). Leaders with integrity always encourage open and honest communication, particularly in discussions that concern decision making. Leaders value the individual's viewpoint and the feedback that results from shared decision making (Parry \& Proctor-Thomson, 2002). This leadership value set is consistent with transformational leadership. Bass and Avolio (1994) state that transformational leadership signifies that 'new ideas and creative problem solutions are solicited from followers, who 
are included in the process of addressing problems and finding solutions'

Parry and Proctor-Thomson (2002) found a positive relationship between perceived leader integrity and transformational leadership. Peterson (2004) asserts that a leader's integrity has a positive influence on the moral intentions of his or her followers.

The value of integrity may have a moderating effect on the relationship between transformational leadership and an ethical climate. According to Palanski and Yammarino (2009), an organisational climate with regard to integrity is positively related to the integrity of leaders. In this study it is postulated that integrity must be based on ethical principles if the leader's actions are to carry any weight in influencing followers to behave ethically. It is argued that integrity moderates the effect of the following dimensions of transformational leadership on an ethical climate:

- Idealised influence: Idealised influence involves the creation of an ethical vision, and the setting of high ethical standards for imitation to achieve this vision. The leader proposes the highest ethical standards to his or her followers, which are implemented in his or her own life, both publicly and privately (Bass \& Steidlmeier, 1999). Idealised influence will only result in followers emulating the leader and buying into his or her vision if these ethical standards are implemented in his or her own life. This display of integrity in the leader's behaviour can lead to building the trust and respect of the followers. Transformational leaders go beyond self-interest and consider the moral and ethical consequences of their actions (Parry \& Proctor-Thomson, 2002).

Consequently, the following can be postulated:

Hypothesis 9: The interaction between integrity and idealised influence produces additional variance in a law and code climate not attributable to the main effect of idealised influence.

Hypothesis 10: The interaction between integrity and idealised influence produces additional variance in a rules climate not attributable to the main effect of idealised influence.

Hypothesis 11: The interaction between integrity and idealised influence produces additional variance in a caring climate not attributable to the main effect of idealised influence.

- Inspirational motivation: The leader challenges followers to participate in shared goals in an ethical manner, and to achieve the vision through personal sacrifice and trust. The leader manifests consistency of word and deed (Bass \& Steidlmeier, 1999; Palanski \& Yammarino, 2009). The leader's efforts at inspirational motivation are likely to fail unless he or she demonstrates integrity. Inspirational motivation will therefore only result in an ethical climate if the leader demonstrates integrity.

From the above assumptions and findings, the following can be postulated:

Hypothesis 12: The interaction between integrity and inspirational motivation produces additional variance in an independence climate not attributable to the main effect of inspirational motivation.

Hypothesis 13: The interaction between integrity and inspirational motivation produces additional variance in a caring climate not attributable to the main effect of inspirational motivation.

\section{RESEARCH DESIGN}

\section{Research approach}

A quantitative or positivistic research approach, and more specifically a cross-sectional, ex post facto design, was used in this study. The positivistic or quantitative approach attempts to explain social phenomena by establishing a relation between variables (Nunnally \& Marlowe, 1997). Questionnaires were used to gather data in a field survey.

\section{Research method Research participants}

In the current study, non-probability sampling, more specifically convenience sampling, was used to select a sample from medium to large companies operating in the Western Cape. The organisations investigated ranged from electricity plants to insurance companies, retailers, accounting firms and banks. A total of 203 completed questionnaires were received, which represents a response rate of $56 \%$. The average age of the respondents was 32.2 years. The sample consisted of both white $(64.2 \%)$ and black $(35.8 \%)$ respondents, was predominantly male $(61.5 \%)$, and the average working experience of employees was 12.4 years. Of the respondents, $58.8 \%$ were working in nonmanagerial positions, $19.1 \%$ in lower-level management, 15.6\% in middle-level management and only $6.5 \%$ in upper-level management positions.

\section{Measuring instruments}

Transformational leadership was measured with the Multifactor Leadership Questionnaire (MLQ) developed by Bass and Avolio (1995). Item analyses produced good reliabilities for the four transformational leadership sub-scales $(0.75 \leq \alpha \leq 0.87)$ (Engelbrecht \& Chamberlain, 2005). A meta-analysis of the MLQ literature was conducted, and it was found that the MLQ scales were reliable and possessed good predictive validity (Lowe, Kroeck \& Sivasubramaniam, 1996).

The ethical climate was measured using Victor and Cullen's (1987) Ethical Climate Questionnaire (ECQ). The measures of each sub-climate have satisfactory reliabilities $(0.65 \leq \alpha \leq 0.82)$ (Victor \& Cullen, 1987). From their analyses, it was concluded that the ECQ scales were adequate for subsequent investigative research (Weber, 1995).

The value of integrity was measured using Butler's Conditions of Trust Inventory (Engelbrecht \& Cloete, 2000). Items measuring honesty, consistency and promise fulfilment were used to form a 12-item Integrity Scale. Scheps (2003) reported satisfactory internal consistency for the Integrity Scale $(\alpha=0.93)$.

\section{Research procedure}

A total of 360 questionnaires were sent out to contact persons in the companies that participated in the survey (see Sample). A covering letter explaining the purpose and content of the study accompanied the questionnaires. Anonymity and confidentiality were assured to participants. The completed questionnaires were returned to the researcher.

\section{Statistical analysis}

The statistical analyses were carried out with the SPSS program (SPSS, 2003). Cronbach alpha coefficients $(\alpha)$ were used to assess the internal consistency of the measuring instruments. Pearson's product-moment correlation coefficients were calculated to establish the strength of the relationships between specific dimensions of transformational leadership and an ethical climate, as proposed in Figure 1. The convention proposed by Guilford (Tredoux \& Durheim, 2002) was used to interpret the correlation coefficients of the sample (see Table 1). Effect sizes were computed to assess the practical significance of relationships in this study. A cut-off point of 0.30 , which represents a medium effect (Steyn, 2002), was set for the practical significance of correlation coefficients.

Unidimensionality was determined by performing unrestricted principal component analyses with Varimax rotation. Standard multiple regression analyses were used to establish whether 
TABLE 1

Guilford's interpretation of the magnitude of significant correlations

\begin{tabular}{ll}
\hline ABSOLUTE VALUE OF R & INTERPRETATION \\
\hline$<0.19$ & Slight; almost no relationship \\
$0.20-0.39$ & Low correlation; definite but small relationship \\
$0.40-0.69$ & Moderate correlation; substantial relationship \\
$0.70-0.89$ & High correlation; strong relationship \\
$0.90-1.00$ & Very high correlation; very dependable relationship \\
$\geq 0.30$ & Practically significant relationship \\
\hline
\end{tabular}

the leadership-integrity interaction effect significantly explains variance in an ethical climate.

\section{RESULTS}

The theoretical model derived from the literature study postulates specific structural relationships between the variables (see Figure 1). The results of the statistical analyses aimed at testing the stated hypotheses are reported below. The treatment of missing values is discussed first, followed by results of the dimensionality analyses and item analyses that were performed to establish the psychometric soundness of the indicator variables used to represent the various latent variables. The results of the correlation and regression analyses are also presented.

\section{Missing values}

It was decided to use imputation as a method to solve the missing values problem and the PRELIS program was used to impute missing values (Jöreskog \& Sörbom, 1996). After imputation, 200 cases with observations on all measured items remained in the validation sample.

\section{Dimensionality analysis}

The aim of the dimensionality analysis was to confirm the unidimensionality of each sub-scale. All four sub-scales of the MLQ passed the unidimensionality test and had satisfactory factor loadings $(0.50<\lambda<0.86)$. Only one of the four sub-scales of the Ethical Climate Questionnaire failed the unidimensionality test. The Caring Climate sub-scale presented a clear two-factor orthogonal factor structure. All items allocated to the subdivided sub-scales loaded satisfactorily $(0.54<\lambda<0.87)$ on a single factor. In the case of the Integrity Scale, the unidimensionality assumption was also not supported. The integrity scale presented a clear, relatively easily interpretable two-factor orthogonal factor structure $(0.48<\lambda<0.91)$. Although the factor fission was found to result in a conceptually meaningful division of a caring climate, as well as the integrity dimension, it was decided that these dimensions would not be extended for the purpose of this article, as doing so would complicate an already complex structural model.

The item analyses produced satisfactory results as all scales and sub-scales exceed the recommended reliability of 0.70 (Nunnally \& Marlowe, 1997). The imputation of missing values, in addition, seems to have had a weak attenuating effect on the coefficient of internal consistency calculated for each sub-scale. The item analyses revealed a limited number of questionable items that had to be considered for possible elimination in a number of the scales and sub-scales. In all such cases it was decided to retain the items in question, primarily due to the marginal increases in the coefficient of internal consistency that would have resulted from the removal of the items.

\section{The relationship between transformational leadership and an ethical climate}

This section focuses on the results as they relate to the main effect hypotheses regarding how transformational leadership affects the dimensions of an ethical climate.

\section{The relationship between intellectual stimulation and an independence climate}

Hypothesis 1 postulated that intellectual stimulation has a positive, linear relationship with an independence climate. The results indicated a slight statistically significant $(\mathrm{r}=0.15$; $p<0.05)$, but not practically significant $(r \leq 0.30)$ correlation between intellectual stimulation and an independence climate (see Table 2) (see also Table 1 for interpretation of correlations). Hypothesis 1 therefore survived the possibility of being refuted. However, only approximately $2 \%$ of the variance in an independence climate can be explained in terms of variance in intellectual stimulation.

The relationship between idealised influence and a law and code climate

Hypothesis 2 suggested that idealised influence positively relates to a law and code dimension of an ethical climate. The results indicated a low, but practically $(r \geq 0.30)$ significant correlation $(r=0.32 ; p<0.001)$ between idealised influence and a law and code climate. Hypothesis 2 was therefore corroborated. Approximately $10 \%$ of the variance in a law and code climate could be explained in terms of variance in idealised influence.

\section{The relationship between idealised influence and a rules climate}

Hypothesis 3 proposed that idealised influence linearly and positively relates to a rules climate. The results indicated a low statistically significant $(r=0.26 ; \mathrm{p}<0.001)$, but not practically significant $(r \leq 0.30)$ correlation between idealised influence and a rules climate. Hypothesis 3 was therefore confirmed. Only approximately $7 \%$ of the variance in this particular ethical climate dimension could be explained in terms of concomitant variance in idealised influence.

\section{The relationship between idealised influence and a caring climate}

Hypothesis 4 proposed that idealised influence has a linear, positive effect on the caring dimension of an ethical climate. The results indicated a substantial and practically $(r \geq 0.30)$ significant relationship $(r=0.49 ; p<0.001)$ between idealised

TABLE 2

Pearson product-moment correlation between integrity, transformational leadership and an ethical climate $(n=200)$

\begin{tabular}{|c|c|c|c|c|}
\hline & INTELLECTUAL STIMULATION & IDEALISED INFLUENCE & $\begin{array}{r}\text { INSPIRATIONAL } \\
\text { MOTIVATION }\end{array}$ & $\begin{array}{l}\text { INDIVIDUALISED } \\
\text { CONSIDERATION }\end{array}$ \\
\hline Law and code & $0.30^{* *}$ & $0.32^{* *}$ & $0.33^{\star *}$ & $0.22^{* *}$ \\
\hline Rules climate & $0.24^{\star *}$ & $0.26^{* *}$ & $0.22^{* *}$ & $0.14^{*}$ \\
\hline Independence & $0.15^{*}$ & $0.20^{* *}$ & $0.33^{* *}$ & $0.22^{* *}$ \\
\hline Caring climate & $0.41^{* *}$ & $0.49^{* *}$ & $0.46^{* *}$ & $0.39^{* *}$ \\
\hline Integrity & $0.57^{\star \star}$ & $0.59^{\star *}$ & $0.49^{\star *}$ & $0.64^{* *}$ \\
\hline
\end{tabular}

${ }^{*} p<0.05-$ statistically significant

** $p<0.01-$ statistically significant 
influence and a caring climate. Hypothesis 4 was therefore corroborated. Approximately $24 \%$ of the variance in this particular ethical climate dimension could be explained in terms of concomitant variance in idealised influence.

\section{The relationship between inspirational motivation and an independence climate}

Hypothesis 5 proposed that inspirational motivation has a linear, positive relationship with an independence climate. The results indicated a low, but practically $(\mathrm{r} \geq 0.30)$ significant correlation $(\mathrm{r}=0.33 ; \mathrm{p}<0.001)$ between inspirational motivation and an independence climate. Hypothesis 5 was therefore supported. However, only approximately $10 \%$ of the variance in this particular ethical climate dimension could be explained in terms of concomitant variance in inspirational motivation.

\section{The relationship between inspirational motivation and a caring climate}

Hypothesis 6 proposed that inspirational motivation has a linear positive relationship with the caring about others dimension of an ethical climate. The results indicated a moderate and practically $(\mathrm{r} \geq 0.30)$ significant correlation $(\mathrm{r}=0.46 ; \mathrm{p}<0.001)$ between inspirational motivation and a caring climate. Hypothesis 6 was therefore corroborated. Approximately $21 \%$ of the variance in the caring ethical climate dimension could be explained in terms of concomitant variance in inspirational motivation.

\section{The relationship between individualised consideration and an independence climate}

Hypothesis 7 proposed that individualised consideration has a linear, positive relationship with an independence climate. The results indicated a low statistically significant $(\mathrm{r}=0.22 ; \mathrm{p}$ $<0.001)$, but not practically significant $(r \leq 0.30)$ correlation between individualised consideration and an independence climate. Hypothesis 7 was therefore confirmed. However, only approximately $5 \%$ of the variance in the independent climate dimension could be explained in terms of concomitant variance in individualised consideration.

\section{The relationship between individualised consideration and a caring climate}

Hypothesis 8 proposed that individualised consideration has a linear, positive relationship with the caring for others dimension of an ethical climate. The results indicated a low, but practically $(r \geq 0.30)$ significant correlation $(r=0.39 ; p<0.001)$ between individualised consideration and the caring climate. Hypothesis 8 was therefore corroborated. Approximately $15 \%$ of the variance in the ethical climate dimension could be explained in terms of concomitant variance in individualised consideration.

The moderating effect of integrity on the relationship between transformational leadership and dimensions of an ethical climate

In the argument presented earlier, which culminated in the structural model depicted in Figure 1, it was contended that the extent to which specific dimensions of transformational leadership will affect specific dimensions of an ethical climate will depend on the extent to which the leader demonstrates integrity. Leadership integrity was therefore postulated to moderate the effect of leadership on an ethical climate.

The moderating effect of integrity on the relationship between idealised influence and a law and code climate

Hypothesis 9 claimed that the interaction between integrity and idealised influence produces variance in a law and code climate that is not attributable to the main effect of idealised influence. The results depicted in Table 3 indicate that the interaction
TABLE 3

Regression of an ethical climate on transformational leadership and the interaction between the dimensions of transformational leadership and integrity

\begin{tabular}{lrrr}
\hline DEPENDENT VARIABLE & PREDICTOR & $\mathbf{F}$ & $\mathbf{p}$ \\
\hline Law and code climate & Idealised influence (II) & 22.565 & 0.000 \\
$\mathrm{R}^{2}=0.112$ & II x Integrity & 2.192 & 0.140 \\
Rules climate & Idealised influence (II) & 13.948 & 0.000 \\
$\mathrm{R}^{2}=0.068$ & II x Integrity & 0.414 & 0.520 \\
Caring climate & Idealised influence (II) & 64.050 & 0.000 \\
$\mathrm{R}^{2}=0.265$ & II x Integrity & 6.843 & 0.010 \\
Independence climate & Inspirational motivation (IM) & 11.721 & 0.001 \\
$\mathrm{R}^{2}=0.066$ & IM x Integrity & 2.274 & 0.133 \\
Caring climate & Inspirational motivation (IM) & 4.897 & 0.028 \\
$\mathrm{R}^{2}=0.273$ & IM x Integrity & 9.214 & 0.003 \\
\hline
\end{tabular}

between idealised influence and integrity did not significantly $(\mathrm{p}>0.05)$ explain variance in a law and code climate when included in a model already containing the idealised influence main effect. Hypothesis 9 was therefore not supported.

Idealised influence did, however, significantly $(\mathrm{p}<0.05)$ explain variance in a law and code climate when included in a model on its own (i.e. when it is allocated all the dependent variable variance it can account for). The ability to account for the variance in a law and code climate in terms of idealised influence was therefore not improved by allowing for different slopes in the regression of a law and code climate on idealised influence.

\section{The moderating effect of integrity on the relationship between idealised influence and a rules climate}

Hypothesis 10 claimed that the interaction between integrity and idealised influence produces variance in a rules climate not attributable to the main effect of idealised influence. Table 3 indicates that the interaction between idealised influence and integrity did not significantly $(p>0.05)$ explain variance in a rules climate when included in a model already containing the idealised influence main effect. Hypothesis 10 was therefore not confirmed. Idealised influence did, however, significantly ( $p$ $<0.05$ ) explain variance in a rules climate when included in a model on its own.

\section{The moderating effect of integrity on the relationship between idealised influence and a caring climate}

Hypothesis 11 claimed that the interaction between integrity and idealised influence produces variance in a caring climate that is not attributable to the main effect of idealised influence. The results (see Table 3 ) indicated that the interaction between idealised influence and integrity did significantly $(\mathrm{p}<0.05)$ explain variance in a caring climate when included in a model already containing the idealised influence main effect. Hypothesis 11 was therefore supported. Idealised influence did significantly $(\mathrm{p}<0.05)$ explain variance in a caring climate when included in a model on its own.

When controlling for the leadership main effect in both the predictor and the criterion, the interaction effect explained approximately $3 \%\left(0.183^{2}\right)$ of the variance in a caring climate. The unique variance in the interaction between idealised influence and integrity explained $2.6 \%\left(0.160^{2}\right)$ of the total variance in a caring climate (i.e. when controlling for the idealised influence main effect in the predictor only). Although the interaction effect explained only a very small percentage of the variance in the caring climate dimension, some support for the postulated moderating role of integrity was nonetheless found. 


\section{The moderating effect of integrity on the relationship between inspirational motivation and an independence climate}

Hypothesis 12 proposed that theinteraction between integrity and inspirational motivation produces variance in an independence climate that is not attributable to the main effect of inspirational motivation. Table 3 indicates that the interaction between inspirational motivation and integrity did not significantly $(p>$ $0.05)$ explain variance in an independence climate when included in a model already containing the inspirational motivation main effect. Inspirational motivation did, however, significantly $(\mathrm{p}<$ 0.05 ) explain variance in an independence climate when included in a model on its own. The ability to account for the variance in an independence climate in terms of inspirational motivation was therefore not improved by allowing for different slopes in the regression of an independence climate on inspirational motivation. No support was therefore found for the hypothesis that the extent to which inspirational motivation affects an independence climate would depend on the extent to which the leader demonstrates integrity.

\section{The moderating effect of integrity on the relationship between inspirational motivation and a caring climate}

Hypothesis 13 proposed that the interaction between integrity and inspirational motivation produces variance in a caring climate that is not attributable to the main effect of inspirational motivation. Table 3 indicates that the interaction between inspirational motivation and integrity significantly $(\mathrm{p}<0.05)$ explains variance in a caring climate when included in a model already containing the inspirational motivation main effect. The ability to account for the variance in a caring climate in terms of inspirational motivation is therefore improved by allowing for different slopes in the regression of a caring climate on inspirational motivation. Support was therefore found for the hypothesis that the extent to which inspirational motivation will affect a caring climate would depend on the extent to which the leader demonstrates integrity. When controlling for inspirational motivation in the predictor and the criterion, the unique variance in the interaction effect explains approximately $5 \%\left(0.211^{2}\right)$ of the variance in a caring climate not explained by the leadership main effect. When controlling for inspirational motivation in the predictor only, the interaction effect explained approximately $3 \%$ $\left(0.184^{2}\right)$ of the total variance in a caring climate. The interaction effect accounted for only a small percentage of the variance in a caring climate.

\section{DISCUSSION}

The aim of the study was to investigate the different relationships between the constructs depicted in the theoretical model (see Figure 1) in the South African context. The results showed positive relationships between the dimensions of transformational leadership and the dimensions of an ethical climate. A positive relationship between intellectual stimulation and an independence climate was found. This implies that leaders who are perceived to practice intellectual stimulation tend to be associated with work units characterised by an independence climate. Followers may perceive a leader who allows them freedom to decide between right and wrong as providing intellectual stimulation.

The results indicated a positive correlation between idealised influence and a law and code climate. This implies that leaders who are perceived to be creating an ethical vision, to have confidence in the vision, and to be setting high ethical standards that are implemented in his or her own life for imitation tend to be associated with work units characterised by a climate that encourages followers to adhere to the laws and codes of the organisation at all times.

It was found that idealised influence positively relates to a rules climate. This implies that the leader who displays idealised influence lives out the ethical standards that he or she has set. Followers will take notice of this role-model of ethical behaviour and emulate it (Bass \& Avolio, 1994), thereby creating a climate of valuing doing things according to the book.

The results indicated a positive relationship between idealised influence and a caring climate. This implies that leaders who are perceived as leading by example will tend to be associated with units characterised by a climate where caring about efficiency and others is held in high regard.

The results showed a positive correlation between inspirational motivation and an independence climate. This implies that inspirational leaders who raise awareness of what is important about a problem and encourage the use of gut feelings or intuition in solving problems (Bass \& Avolio, 1994) will tend to be associated with the independent dimension of an ethical climate.

A positive relationship was found between inspirational motivation and a caring climate. This is consistent with the literature study (Banerji \& Krishnan, 2000; Bass \& Avolio, 1994; Odom \& Green, 2003), which implies that inspirational leaders are likely to improve the enabling and empowerment of their followers and their commitment to searching for solutions to problems, which, in turn, will lead to the development of the caring dimension of an ethical climate.

The results indicated a positive relationship between individualised consideration and an independence climate. This is consistent with the proposition, which implies that leaders exhibiting individualised consideration care about the followers' need to make their own decisions about what is ethical or not and thereby contribute to the development of an independent ethical climate.

The results demonstrate that individualised consideration has a positive relationship with the caring dimension of an ethical climate. This is consistent with the literature study, which implies that leaders who are individually considerate consider the best interests of others, in taking the needs and interests of the followers into account (Bass \& Avolio, 1994). This contributes to the development of a caring ethical climate, as employees are not interested in their own needs only, but also in the needs of others and that of the work unit.

These findings are consistent with other studies that suggest that transformational leaders exercising idealised influence, intellectual stimulation, inspirational motivation and individualised consideration will contribute to the development of an ethical culture in organisations (Banerji \& Krishnan, 2000; Bass \& Avolio, 1994; Bass \& Steidlmeier, 1999; Ciulla, 2004; Kanungo \& Mendonca, 1996; Odom \& Green, 2003). The study therefore affirmed that transformational leaders within an organisation can help create and perpetuate an ethical climate.

In the theoretical argument, which culminated in the structural model depicted in Figure 1, it was contended that the extent to which specific dimensions of transformational leadership will affect specific dimensions of an ethical climate would depend on the extent to which the leader demonstrates integrity. Leadership integrity was therefore postulated to moderate the influence of leadership on an ethical climate. Support for this hypothesis was found regarding two relationships only, namely between idealised influence and a caring climate, and between inspiration motivation and a caring climate. However, the interaction effect accounted for only a small percentage of the variance in a caring climate.

Integrity was, however, found to correlate strongly and significantly with all the dimensions of transformational leadership $(0.49 \leq \mathrm{r} \leq 0.64)$ (see Table 2). This finding is 
consistent with other studies that identified integrity as a core value of transformational leadership (Bass \& Steidlmeier, 1999; Palanski \& Yammarino, 2009; Parry \& Proctor-Thomson, 2002; Petersen, 2004; Storr, 2004; Yukl, 2006).

\section{Limitations and recommendations}

A possible limitation of this study is that of mono-method bias or common-method variance. The problem derives from the fact that the source of the data for the predictors was not separated from the source of their outcomes. Any relationship that existed could therefore be attributed to the response bias on the part of the respondent.

Figure 1 proposes causal linkages between specific dimensions of transformational leadership and specific dimensions of an ethical climate. The foregoing discussion revealed some degree of support for the proposed linkages within the limitations set by the ex post facto and the cross-sectional nature of the research design. The model, however, did not take into account all the possible relationships between the facets of transformational leadership and the dimensions of an ethical climate. The results indicated that some of the relationships not anticipated by the model were stronger than those anticipated by the model (see Table 2). These results may have added value to the present study by providing valuable insights into the moderating effect of integrity on the relationship between transformational leadership and the development of an ethical climate.

There are basically three ways in which integrity could enhance our understanding of the leadership process: integrity could be an independent factor that explains additional variance in an ethical climate; integrity could be causally prior to transformational leadership; or integrity could moderate the transformational leadership-ethical climate relationship. Although no convincing support was found for the proposition that integrity has a moderating effect on the relationship between the dimensions of transformational leadership and the dimensions of an ethical climate, the results would rather suggest a direct relationship between integrity and transformational leadership. This means that integrity can influence an ethical climate indirectly through transformational leadership. It is therefore recommended that an alternative structural model could be developed that postulates that transformational leadership dimensions may mediate the relationship between integrity and the dimensions of an ethical climate. This alternative model should be tested through structural equation modelling to better understand the interaction effects among the variables.

\section{Conclusion}

The positive relationship between transformational leadership and an ethical climate emphasises the importance of transformational leadership behaviourwhenethical organisations are developed. The leader is responsible for setting ethics or norms that govern the conduct of employees in the organisation, and it is vital that the work climate of the organisation encourages ethical behaviours (Kouzes \& Posner, 2007; Palanski \& Yammarino, 2009; Spangenberg \& Theron, 2005).

Every organisation needs some form of ethical programme to effectively manage its ethical culture and to create and maintain a culture that promotes ethical behaviour. In order to strengthen the corporate ethical culture, some structural and procedural changes could be implemented by management as a means of institutionalising ethics (McDonald, 2009; Van Velsor \& Ascalon, 2008; Vitell \& Hidalgo, 2006). These changes include corporate ethical code promulgation and value statement formulations; management ethical training and corporate ethical education; corporate ethical performance evaluation; disciplinary procedures in place for breach of codes; procedures for seeking advice or reporting violations (e.g. the support of whistleblowers, ethical hotlines); equitable reward systems; conducting of ethical audits; and the introduction of an ethics ombudsperson, ethics committees and ethics newsletters.
Effective and well-designed leadership development programmes may support ethical action by providing participants with opportunities for rich and comprehensive feedback, enhancement of self-awareness, time to reflect on personal and professional relationships, and improved understanding of the ethical intent of strategic processes (Van Velsor \& Ascalon, 2008). It is therefore crucial that management create an organisational culture of openness and transparency in which unethical conduct will become visible and in which employees and managers can call each other to account.

Ethical leadership demonstrates the will and ability to strategically position, design and sustain an organisation successfully, to develop employee competence and to direct human and organisational energy in pursuit of performance and achievement that stand the ethical test of effectiveness and efficiency (Malan \& Smit, 2001). The building of an ethical climate requires more than just leaders who behave ethically; it requires the proactive management of ethics. Such leaders have to be passionately motivated and committed to achieve the vision of an ethical organisational climate (Spangenberg \& Theron, 2005). The ethical responsibility of leadership is to take the lead in defining a sound value system. The best way to achieve this is by uncompromisingly and openly living such a value system (Banerji \& Krishnan, 2000; Malan \& Smit, 2001). When leaders act consistently and sincerely on the basis of their values, their authenticity will be demonstrated to others over time, and their followers will be loyal to them.

Ethical leadership is leadership that is capable of identifying ethical issues when they inevitably arise, utilising an ethical decision-making process for resolving ethical disputes and having the courage to make the ethical decision (Odom \& Green, 2003). A fundamental commitment to high ethical standards must permeate everything employees do and must be a foundation of action of leaders throughout the organisation. When leaders are truly transformational, and serve as role models of ethical behaviour, a positive culture will permeate the whole organisation. Adherence to the highest standards of ethical behaviour and integrity inspires confidence and trust, both inside and outside the organisation.

\section{REFERENCES}

Banerji, P., \& Krishnan, V.R. (2000). Ethical preferences of transformational leaders: An empirical investigation. Leadership and Organization Development Journal, 21(8), $405-$ 413.

Bass, B.M., \& Avolio, B.J. (1994). Improving organizational effectiveness through transformational leadership. Thousand Oaks: Sage.

Bass, B.M., \& Avolio, B.J. (1995). The multifactor leadership questionnaire (Form 5-45). Palo Alto: Consulting Psychologist Press.

Bass, B.M., \& Steidlmeier P. (1999). Ethics, character, and authentic transformational leadership behavior, Leadership Quarterly, 10(2), 181-217.

Burns, J.M. (1978). Leadership. New York: Harper \& Row.

Carlson, D.S., \& Perrewe, P.L. (1995). Institutionalisation of organisational ethics through transformational leadership. Journal of Business Ethics, 14(10), 828-838.

Ciulla, J.B. (2004). Ethics, the heart of leadership. Westport: Praeger Publishers.

Cohen, D.V. (1993). Creating and maintaining ethical work climates: Anomie in the workplace and implications for managing change. Business Ethics Quarterly, 3(4), 343-358.

Davis, A.L., \& Rothstein, H.R (2006). The effects of the perceived behavioural integrity of managers on employee attitudes: A meta-analysis. Journal of Business Ethics, 67, 407-409.

Engelbrecht,A.S.(2001).Corevaluesunderlying transformational and transactional leadership. Management Dynamics, 10(3), 56-80. 
Engelbrecht, A.S., \& Chamberlain, L. (2005). The influence of transformational leadership on organisational citizenship behaviour through justice and trust. Management Dynamics, 14(1), 2-13.

Engelbrecht, A.S., \& Cloete, B.E. (2000). An analysis of a supervisor-subordinate trust relationship. Journal of Industrial Psychology, 26(1), 24-28.

Fulmer, R.M. (2004). The challenge of ethical leadership. Organizational Dynamics, 33(3), 307-317.

Jones, G.R. (2007). Organizational theory, design, and change. Upper Saddle River: Prentice Hall.

Jöreskog, K., \& Sörbom, D. (1996). LISREL 8: User's reference guide. Chicago: Scientific Software International.

Kanungo, R.N., \& Mendonca, M. (1996). Ethical dimensions of leadership. Thousand Oaks: Sage.

Kidwell, R.E., \& Martin, C.L. (2005). Managing organizational deviance. New York: Sage.

Kouzes, J.M., \& Posner, B.Z. (2007). The leadership challenge. San Francisco: Jossey-Bass.

Krafft, P., Engelbrecht, A.S., \& Theron, C.C. (2004). The influence of transformational and transactional leadership on dyadic trust relationships through perceptions of fairness. South African Journal of Industrial Psychology, 30(1), 18-26.

Lowe, K.B., Kroeck, K.G., \& Sivasubramaniam, N (1996). Effectiveness correlates of transformational and transactional leadership: A meta-analytic review of the MLQ literature. Leadership Quarterly, 7, 385-426.

Malan, F., \& Smit, B. (2001). Ethics and leadership in business and politics. Cape Town: Juta.

McDonald, G.M. (2009). An anthology of codes of ethics. European Business Review, 21(4), 344-372.

Mikulay, S., \& Goffin, R.D. (2007). Measuring and predicting counterproductivity in the laboratory using integrity and personality testing. Educational and Psychological Measurement, 58(5), 768-791.

Nunnally, R.C., \& Marlowe, H.A. (1997). Psychometric theory. New York: McGraw-Hill.

Odom, L., \& Green, M.T. (2003). Law and the ethics of transformational leadership. Leadership and Organization Development Journal, 24(2), 62-69.

Ones, D.S., Viswesvaran, C., \& Schmidt, F.L. (2003). Personality and absenteeism: A meta-analysis of integrity tests. European Journal of Personality. 17, 19-38.

Palanski, M.E., \& Yammarino, F.J. (2007). Integrity and leadership: Cleaning the conceptual confusion. European Management Journal, 25(3), 171-184.

Palanski, M.E., \& Yammarino, F.J. (2009). Integrity and leadership: A multi-level conceptual framework. The Leadership Quarterly, 20, 405-420.
Parry, K.W., \& Proctor-Thomson, S.B. (2002). Perceived integrity of transformational leaders in organisational settings. Journal of Business Ethics, 35, 75-96.

Peterson, D. (2004). Perceived leader integrity and ethical intentions of subordinates. Leadership and Organization Development Journal, 25, 7-23.

Rossouw, G.J. (1997). Business ethics in South Africa. Journal of Business Ethics, 16, 1539-1547.

Scheps, A. (2003). The influence of ethical values on transformational leadership and ethical climate in organisations: An exploratory study. Unpublished Masters thesis, Stellenbosch University, Stellenbosch, South Africa.

Spangenberg, H., \& Theron, C.C. (2005). Promoting ethical follower behaviour through leadership of ethics: The development of the ethical leadership inventory (ELI). South African Journal of Business Management, 36(2), 1-18.

SPSS (2003). SPSS 12.0 for Windows. Chicago.

Steyn, H.S. (2002). Practical significant relationships between two variables. South African Journal of Industrial Psychology, 28(3), 10-15.

Storr, L. (2004). Leading with integrity: A qualitative research study. Journal of Health Organization and Management, 18(6), 415-434.

Tredoux, C.T., \& Durheim, K. (2002). Numbers, hypotheses and conclusions: A course in statistics for the social sciences. Cape Town: UCT Press.

Van Velsor, E., \& Ascalon, E. (2008). The role and impact of leadership development in supporting ethical action in organizations. Journal of Management Development, 27(2), 187-195.

Victor, B., \& Cullen, J.B. (1987). A theory and measure of ethical climate in organisations. In W.C. Frederick \& L.E. Preston (Eds.), Research in corporate social performance and policy (n.p.). Greenwich: Jai Press.

Victor, B., \& Cullen, J.B. (1988). The organisational bases of ethical work climates. Administrative Science Quarterly, 3(1), 101-125.

Vitell, S.J., \& Hidalgo, E.R. (2006). The impact of corporate ethical values and enforcement of ethical codes on the perceived importance of ethics in business: A comparison of US and Spanish managers. Journal of Business Ethics, 64, 31-43.

Weber, J. (1995). Influences upon organisational ethical subclimates: A multi-departmental analysis of a single firm. Organization Science, 6 (5), 509-523.

Yukl, G. (2006). Leadership in organisations. Upper Saddle River: Prentice Hall. 